\title{
绩效管理在建筑企业人力资源管理中的应用
}

薛琼

桂林市金辉建设发展有限公司

DOI:10.32629/btr.v2i8.2447

[摘 要] 人力资源管理在企业经营发展中占有重要地位, 而绩效考核作为人力资源管理中较为重要的一环, 其不仅对人员聘 用有着直接影响, 也对人员的调度、晋升级薪酬待遇有着决定性作用。对于建筑行业来说, 由于人员流动性较大, 要想增强自身 的竞争实力,就需要加大人力资源管理力度,建立完善的绩效管理制度,从而推动企业的有效运转。

[关键词] 绩效管理; 建筑行业; 人力资源管理

绩效管理是人力资源管理的重要手段, 相关人员需创新 管理效能, 在量化考核和效能考核上对职工的工作情况进行 综合性管理。同时, 绩效管理能够激发员工的工作热情, 不断 提高员工的工作效率, 进而为建筑企业发展贡献更多力量。 因此, 探究绩效管理在建筑企业人力资源管理中的应用是尤 为必要的。

\section{1 绩效管理的含义及特点}

绩效管理是为实现企业管理目标的有效手段, 是巩固企 业既定发展目标, 推动个人或团队开展相关建设活动的重要 方法。绩效管理能够充分调动员工的工作热情, 使其严格按 照企业要求开展各项活动项目, 并在此过程中逐渐增大企业 的经济效益, 为企业持续发展做出贡献。

\section{2 绩效管理在建筑企业中的重要意义}

2.1有利于选拔合适的人才

在建筑企业中, 绩效管理和人才选拔之间存在相互作用 的关系。绩效管理是检验人才专业节能和综合素质能力的基 础, 而人才的个人能力则是决定绩效管理结果的关键要素。 通过绩效管理能够为人才选拔指明方向, 为企业发展奠定坚 实基础。

2.2 有利于完善奖惩制度内容

奖惩制度制定的合理性对于增强员工工作积极性有着 重要作用。要想保证奖惩制度制定的合理性, 就必须依靠绩 效考核的相关内容, 及时了解员工的工作和生活情况, 综合 评定分析, 确定明确的奖惩措施和内容, 进而营造良好的工 作氛围。

\section{3有利于实现按劳分配}

按劳分配可以说是目前我国公信力最高的一种分配原 则, 其是按照劳动数量及质量分配一定的薪酬费用, 满足人 们的正常生活。因此, 在绩效管理中, 应确保劳动数量和质量 的准确性, 这样才能更好的提升考核制度的精准性, 改善绩 效管理的综合水平。在建筑企业管理中, 需要的技术人员相 对较多, 其薪资待遇的组成是通过基本工资+浮动工资实现 的, 其中的浮动工资就是所说的绩效工资, 其需要通过员工 能力的综合评定方能准确发放, 以此来调动员工的工作积极 性, 更好的发挥出自身潜能, 为建筑企业发展做出贡献。

\section{4有利于员工职位晋升和调配}

在建筑企业发展中, 充分发挥员工自身的潜能对于提高 工作效率和质量, 实现企业的创新与优化有着重要作用。而 绩效考核管理则是明确员工自身潜能, 实现合理调配及激发 潜能的重要措施。通过绩效考核, 可以使员工及时发现自身 的能力, 并对超出现有岗位能力的员工予以技术上的培训, 以促进其潜能的有效发挥; 而对于一些能力不足的员工, 通 过绩效考核, 可对其进行适当调度, 安排合适岗位供其进一 步学习; 对于不适合现有岗位的员工, 则可以通过绩效考核 及跨岗交流, 将其安排到合适的部门中, 以达到知人善用的 目的, 保证企业各项活动的有序进行, 加强业务完成效果。

\section{5有利于开展员工培训}

要想提高人力资源管理水平, 有针对性的开展员工培训 活动是尤为重要的。只有这样才能不断优化员工自身能力水 平, 及时了解先进技能知识, 并为后期业务开展提供帮助。同 时培训活动的开展也能够帮助管理层人员及时掌握员工的 具体情况, 做好员工的检验工作, 进而实现人员的合理划分, 推动企业自身的良性发展。

\section{3 绩效管理在建筑企业人力资源管理中的应用现状}

3. 1 完整性较差

建筑企业人力资源管理中的绩效管理在落实过程中, 应 结合奖惩制度的合理应用, 调动员工工作积极性, 激发员工 的良性竞争精神, 不断优化员工自身的绩效水平, 以此带动 企业绩效的整体提升。不过结合目前实际情况来看, 企业制 定的奖惩制度在落实过程中存在诸多问题, 根本无法调动员 工工作的积极性, 再加上绩效考核表面化现象较为严重, 这 使得绩效管理的作用得不到充分发挥, 严重影响了建筑企业 人力资源管理工作的开展, 并为企业发展带来了阻碍。

3.2 绩效考核制度缺乏完善性

一些建筑企业在绩效考核落实上存在着形式化现象, 制 度落实不到位、监管力度不严、制度内容与实际要求不符等, 这使得员工在工作中产生较多不良情绪, 影响了绩效管理功 效的发挥。此外, 个别建筑企业在绩效考核结果上存在有失公 允的情况, 考核期间极易被人为因素所干扰, 这也为考核结果 带来了不利影响, 从而导致考核的准确性与真实性不断下降。 


\section{3缺少反馈和改进环节}

建筑企业绩效管理中, 很多员工都不清楚绩效管理的作 用及影响效果, 在落实绩效管理的相关内容时, 也多是以员 工基础能力考核为主, 习惯以考核结果来评定员工的实际行 为, 缺少反馈这一环节, 这使得绩效考核中存在的一些问题 得不到及时解决, 影响了考核的准确性, 削弱了企业人力资 源管理的整体效果。另外, 当建筑企业人力资源管理应用绩 效管理手段时, 缺乏相应的改善环节, 无法妥善处理考核结 果, 整体反馈情况无法得到有效的分析与处理, 不能解决企 业应用绩效管理时出现的问题。

\section{4 绩效管理在建筑企业人力资源管理中的应用}

4. 1 强化员工的绩效管理意识

人力资源管理中的绩效管理, 其主要目的就是规范员工 的标准行为, 保证企业各项业务活动的顺利开展。为此, 在绩 效管理中, 首要工作就是深化员工的绩效管理意识, 让其明 确绩效管理的重要性, 转变传统管理思想带来的束缚, 进而 促进绩效管理相关体系制度的落实和完善, 改善企业管理水 平。另外, 在绩效管理中, 应将理论与实践活动有效结合起来, 加强企业与员工之间的互动交流, 积极听取员工意见, 不断 完善绩效管理的内容, 提高绩效管理质量, 促进其功效的发 挥。再者, 建筑企业要注重对员工管理理念的培养, 这对企业 的日后发展是极为有利的, 通过提升员工执行能力与工作效 率, 可以为企业经营管理活动的顺利开展创造有利条件。

\section{2 合理规划绩效考核内容}

建筑企业绩效考核在制定中,一方面要结合具体规范内 容, 另一方面还应对现有的实际情况予以综合考量, 加强绩 效考核制定的标准性, 有效性, 保证其落实效果。在考核标准 明确上, 也应结合员工的实际情况, 确保其普遍性和可行性, 这样才能充分发挥出考核制度的激励作用, 调动员工工作积 极性, 从而改进工作质量, 提升企业的经济效益。

\section{3 建立完善的考核制度}

完善考核制度的相关内容, 提升规范化管理水平, 对于 实现绩效管理目标有着重要意义。而且完善考核制度的相关 内容, 也是提高绩效管理工作效率, 发挥人力资源管理作用 的具体措施。建筑企业在绩效管理过程中, 需结合发展需求 不断完善绩效考核的内容和要求, 并以此为基础加大对员工 的监管力度, 避免违法、违规等现象的出现, 从而增强绩效管 理的公平性、公正性, 确保员工自身能力的充分发挥。另外, 在考核过程中, 对于表现优异的员工需给与一定的奖励, 调
动其工作积极性。对于违规的员工要给与其适当的惩罚, 引 以为戒, 从而完善员工自身专业素养, 增强员工对企业的认 同感, 时其为企业发展做出贡献。

\section{4优化绩效管理体系}

为解决绩效管理中存在的问题, 建筑企业应加大对绩效 管理体系的优化力度, 健全管理制度, 全面落实管理内容, 以 推动建筑企业长远发展目标的实现。同时在绩效管理优化中, 要加强与员工之间的沟通交流, 及时发现问题、解决问题, 促进绩效管理功效的充分发挥。在考核过程中,一方面要明 确考核标准,一方面需对各项考核指标进行量化处理, 实现 绩效管理的合理调整, 优化企业管理水平。再者, 建筑企业要 将员工的职能分配明确下来, 考虑到员工实际专业优势, 逐 步优化人员配置, 使绩效管理作用得到充分体现, 实现企业 竞争力的增强。

4.5 建立以绩效为主导的企业文化

将绩效管理与建筑企业文化结合起来, 能够建立一个公 平、公正的竞争环境, 营造良好的工作氛围。在这样的环境 下, 员工自身的潜能也能够被进一步的发挥出来, 并以此来 为企业整体绩效的提升奠定基础。另外，以绩效为主导的企 业文化, 对员工也有着明显的鼓励作用。企业文化作为企业 的支柱, 在企业发展中有着很好的导向作用, 通过绩效管理 与企业文化的有机结合, 可以为企业的良性发展创造更多优 质环境。

\section{5 结语}

总之, 在建筑企业的日常管理中, 人力资源管理工作的 开展与绩效管理工作的有效落实有着密不可分的联系。只有 切实发挥出绩效考核工作的实际效用, 才能更好的改善人力 资源管理的综合水平, 进而为建筑企业发展及竞争实力的增 强贡献力量。为此, 在实际管理中, 管理者应督促员工全面落 实各项工作, 实现对员工自身专业技能和素质的全面考察, 调动其工作积极性, 以此为建筑企业的长远发展提供动力。

\section{[参考文献]}

[1]张娟.试论绩效管理在建筑企业人力资源管理中的 应用 [J].人才资源开发,2019(01):71-72.

[2]凌耀.浅析绩效管理在建筑企业人力资源管理中的应 用[J].办公室业务,2018(18):168.

[3]熊杨波.建筑施工企业人力资源管理创新[J]. 管理观 察,2019(16):17-18. 